\title{
EDUCACIÓN
}

\section{Factores que influyen en la elaboración de tesina según egresados de la Carrera de Obstetricia. Universidad Nacional de Asunción. Paraguay, 2014}

\author{
Elena María Rodríguez Oliveira ${ }^{1}$
}

\section{Resumen}

Introducción: Las universidades son responsables de la producción de conocimiento en la sociedad, son las que contribuyen en la resolución de problemas; generando beneficios a corto, mediano y largo plazo (Alosilla, 2009). A nivel mundial $70 \%$ de los estudiantes universitarios, indican presentar dificultades para iniciar la elaboración de tesis, pese a su importancia y necesidad como requisito para optar por un título profesional, debido a varios factores, de tipo motivacional, personal hasta los institucionales (Arredondo, 2000). Al finalizar la carrera, el estudiante debe realizar un trabajo final de investigación y, lograr que sea aprobado. A menudo, esté enfrenta esta tarea, sin estar familiarizado con trabajos de este tipo. El estudiante ha tenido escasas oportunidades de contactar con informes y comunicaciones que traten conocimientos en estado naciente (Grasso, 2012).

Uno de los aspectos que explica la deserción y las bajas tasas de graduación es precisamente la tesis y los procesos asociados a ella. Los alumnos aprueban los cursos, pero no logran plantear un proyecto, desarrollarlo y culminarlo con éxito. El proceso mismo de la elaboración de la tesis genera sentimientos desfavorables a su terminación: generalmente se observa disminución de la autoestima; bloqueos, falta de voluntad para continuar, dudas neuróticas, hipercrítica hacía sí mismo, desvalorización de pensamientos auto descalificadores, obsesivos, desamparo, profecías negativas de auto cumplimiento, dificultad en tomar decisiones. El bloqueo mental lleva al estudiante a dilatar la escritura y en muchos casos a abandonar su tesis, porque cuando una persona elabora una tesis vive conflictos cognitivos y emocionales que producen una inactividad académica por tiempos prolongados (Ochoa Sierra, 2011).

Objetivo: Determinar los factores que influyen en la elaboración de tesina según egresados de la Universidad Nacional de Asunción, Paraguay.

1. Universidad Nacional de Asunción. Facultad de Enfermería y Obstetricia. Coordinación de Investigación.

Tesis de Maestría presentada en la Facultad de Filosofía de la Universidad Nacional de Asunción. E-mail: elenamariapy@hotmail.com

DOI: $10.26885 /$ rcei.foro.2018.60 
Material y Método: Diseño observacional, tipo de estudio descriptivo, de corte transversal, enfoque cuantitativo. Universo 447 egresados de la Carrera de Obstetricia, muestra 291 egresados, muestreo probabilístico, aleatorio simple; método la encuesta, técnica la entrevista, instrumento el cuestionario, el mismo fue administrado a través de: entrevista personalizada; vía mail y celular. Los datos fueron cargados en una planilla electrónica Microsoft Excel 2010, fue depurada a fin de evitar inconsistencias en la base de datos; procesados por medio del programa Epi-Info 7.2 En todo momento se consideraron los principios éticos de la investigación.

Resultados: Las características socio demográficas de egresados, grupo etáreo mayoritario representa de 30 a 39 años, (52\%), con predominio del sexo femenino (91\%).

Factor estudiantes: personal influye 73\%, académico 57\% influye; institucional: recursos humanos $71 \%$ influye, biblioteca $65 \%$ influye, malla curricular y organizacional $59 \%$ influye. Otros: lenguaje común $94 \%$ influye; exigencias institucional 67\% influye; incentivo (desarrollar cultura científica) $64 \%$ influye; grado de escolaridad (padres) 55\% influye, los resultados evidencian que el factor personal académico del estudiante y lenguaje común son los que mayor dificultades presentan durante el proceso de elaboración de tesina.

Conclusiones: Se concluye que los factores que influyen en la elaboración de tesina, según orden de factores constituyen lo de estudiante (personal), institucional (recursos humanos) y otros (infraestructura).

Palabras clave: factores, influyen, elaboración de tesina.

\section{RefEREnCias}

Alosilla Díaz, J. (2009). Factores que influyen en la decisión de realizar una tesis para optar el título profesional de cirujano dentista, en estudiantes de la Facultad de Odontología (Tesis). Lima: Universidad Nacional Mayor de San Marcos, Facultad de Odontología. EAP de Odontología.

Arredondo, M., Flores, A. (2000). El proceso de graduación. México: UNAM.

Carruyo Del Castillo, J. (2007). Conversando con tutores y asesores de tesis. Revista Visión Gerencial, 6, p. 45-54.

Grasso. L. (2012). Dificultades frecuentes en la elaboración de provectos de trabajos de investigación y trabajos finales, (1), p. 136-156.

Ochoa Sierra, L. (2011). La elaboración de una tesis de maestría: exigencias y dificultades percibidas por sus protagonistas: artículo, reporte de caso. Entornos, (24), p. 171-183. 